\title{
AN OVERVIEW OF SOME OF THE KEY LEGAL DEVELOPMENTS IN HIV/AIDS AND THE LAW - 2003
}

\author{
Liesl Gerntholtz, $B A, L L B$ \\ Head, Legal Unit, AIDS Law Project, and Centre for Applied Legal Studies, University of the Witwatersrand, fohannesburg
}

\begin{abstract}
South Africa has a strong legal framework that offers a high level of protection to people living with HIV/AIDS. Although the Constitution does not explicitly refer to HIV/AIDS, it does prohibit unfair discrimination on the grounds of disability. International jurisprudence has developed a broad definition of 'disability', which goes beyond so-called functional disability and has successfully accommodated HIV-related discrimination cases in Australia, Canada and the USA. It is likely that South African courts will ultimately do the same.
\end{abstract}

Employment legislation does refer specifically to HIV-related discrimination and prohibits unfair discrimination on the grounds of HIV status in the workplace. Pre-employment and employment HIV testing is prohibited, unless the permission of the Labour Court is obtained before to testing takes place. There are other laws, dealing with the provision of medical aid services, access to education and health care, that also prevent HIV-related discrimination.

Despite this, however, people with HIV/AIDS continue to suffer high levels of discrimination and prejudice. The disclosure of HIV status remains a fearful experience for many South Africans and may well be accompanied by violence and economic and social deprivation.

This article examines some of the most important cases that have come before the courts and other tribunals in 2003 and have sought to establish the rights of people with HIV/AIDS to live lives of dignity without fear.

\section{CHILDREN}

As the epidemic has developed, issues relating to children and the impact of HIV have begun to gain prominence. The two cases described below illustrate some of the complexities involved in children's rights and HIV/AIDS.

\section{THE RIGHT TO EQUALITY IN ACCESS TO EDUCATION}

The Buccleuch Montessori Nursery School case garnered much publicity when it was argued in September 2002. The case concerned the right of Tholakele Nkosi, then 3 years old, to attend the private nursery school. The applicant in the case, Karen Perreira, Tholakele's foster mother, had elected to disclose Tholakele's HIV status to the school, believing that it was in the child's best interest for the school to be aware of her medical condition.

The response of the school was extraordinary in the context of a severe AIDS epidemic well into its second decade fears were expressed about the risks of transmission as a result of biting, scratching insect bites and sharing sweets. The school also indicated that it did not consider itself equipped to admit a child with HIV as none of its teachers had received any training in this regard.

In order to counter these allegations, expert affidavits dealing with the risks of HIV transmission in the school setting, evidence regarding the non-discrimination policy of the Department of Education and international case law were put before the court.

A dispute existed between the parties as to whether Tholakele's application for admission was actually rejected. According to the school's own version, however, it conceded that a recommendation had been made to defer the application until such time as the school considered itself ready to admit children with HIV and until Tholakele was 'past the biting stage'. It was argued that this conduct, on its own, constituted unfair discrimination against Tholakele.

Judgment was handed down more than a year later, in September 2003. Disappointingly, Judge Lucy Mailula found that since the school had not made a final decision 
to exclude Tholakele, its conduct did not amount to unfair discrimination. The judge did not deal with the implications of the recommendation to defer Tholakele's admission and the discrimination inherent in such conduct and dismissed the application with costs.

In my view, the judgment is a dangerous one as it allows a school to effectively exclude a child with HIV as long it 'defers' the application, rather than rejects it outright. The judgment provides no guidance as to the basis on which such a deferral may take place, how long the application may be deferred and what steps a school should take to accommodate children with HIV. The judgment may also serve as a precedent for other settings where service providers wish to exclude people with HIV.

The judgment is currently being appealed.

\section{CHILDREN AND CONSENT TO HIV TESTING AND TREATMENT}

South African law requires that parental consent be obtained before any medical treatment can be given to a child below the age of 14 years. The Child Care Act 74 of 1983 permits the Minister of Social Development to consent to the treatment in the absence of consent from a parent or legal guardian, and a medical superintendent may consent in urgent cases. The High Court, as the upper guardian of all children, may also be approached to provide consent.

The Wits Paediatric HIV Working Group (WPHWG) provides treatment and care to children in the public sector and to children and infants in children's homes. Increasing numbers of children with HIV who require treatment and care are presenting at hospitals without parents or legal guardians. For these children, there is no person who is legally capable of providing consent to treatment and HIV testing. A similar situation has arisen in children's homes, where there are significant numbers of children, particularly newborn babies, who have not been lawfully placed in the custody of the homes.

The WPHWG wished to provide a high level of treatment and care to these vulnerable children and was extremely concerned about how the requirement of consent could be dealt with. It was the view of the WPHWG that consent plays a crucial role in empowering patients and their caregivers to participate in decisions about their health and also protects the health worker.

Three cases were brought in 2003, dealing with consent. The first two merely sought permission from the court for five orphans without legal guardians to commence antiretroviral treatment. Although both applications were successful, it was clear that it would be difficult, timeconsuming and expensive to approach the High Court for each child in respect of whom consent could not be obtained. Attempts were then made to use the mechanism created by the Child Care Act that allowed for ministerial consent to be obtained where parental consent could not. The Minister of Social Development responded promptly to the first request and gave his permission for the children named in the letter to receive treatment. However, he failed to respond to any further requests and a third court application was then brought.

The third application attempted to create a mechanism that would facilitate the care of these children, without eroding the need to obtain consent, and was much broader in scope than the first applications. The order granted by the court permits the doctors associated with the WPHWG to obtain consent from the person who has daily care of the child, once they have certified that the test or treatment is in the best interests of the child. This approach is in line with the current proposals in the Children's Bill (a draft act that has not yet been enacted), which gives limited legal recognition to caregivers and allows them to consent to medical treatment.

Although the case represents an important victory for children, its application is limited to the WPHWG and it will not assist other doctors. It is unlikely that the Children's Bill will become law in the near future and it is therefore extremely important that the issue of consent be dealt with in the interim period. If it is not, doctors who treat children with HIV will be forced to either exclude children without legal guardians, or to act without consent. Neither situation is desirable.

\section{HEALTH CARE}

\section{VRM V. THE HPCSA}

A key case dealing with the role of the Health Professions Council of South Africa (HPCSA) in regulating the medical profession was finalised in 2003. The case concerned a pregnant woman with HIV who was tested during her pregnancy without her consent. The doctor who performed the test did not disclose the results of the test to his patient and failed to advise her of the steps she could take to reduce the risk of perinatal HIV transmission. The patient subsequently delivered a stillborn baby and was advised that she had HIV shortly after the birth.

A complaint was referred to the HPCSA, and although the doctor conceded that he had tested the patient without her informed consent and had not disclosed her test result, the HPCSA declined to convene a disciplinary hearing. Its 
Committee of Preliminary Enquiry accepted the version of the doctor, that he had acted 'out of compassion', and declined to take the matter any further.

The judgment on appeal criticised the failure of the HPCSA adequately to consider the facts of the case and indicated that the procedures of the Committee of Preliminary Enquiry were flawed. The judgment examined the role of this committee and indicated that it did not have the power to merely accept the version of the doctor over that of the patient, which it routinely does, unless the evidence provided by the doctor is corroborated. The matter has been referred back to the HPCSA for proper consideration.

Several other complaints, which the HPCSA had also failed to deal with properly, will also be reconsidered in light of the judgment.

A civil claim for damages against the doctor is pending.

\section{ACCESS TO AFFORDABLE ANTIRETROVIRAL MEDICINES}

In September 2002, a complaint was lodged with the Competition Commission against two major pharmaceutical companies, GlaxoSmithKline and Boehringer Ingelheim, on behalf of various applicants, including four people living with HIV, the Treatment Action Campaign, COSATU and the AIDS Consortium.

The complaint alleged that the two companies were acting unlawfully by charging excessive prices for certain antiretroviral drugs. The complaint stated that the prices charged were directly responsible for the 'premature, predictable and avoidable deaths of women, men and children living with HIVIAIDS.

In October 2003, the Commission announced that it had decided to refer the complaint to the Competition Tribunal for adjudication.

On 9 December 2003, a landmark agreement was reached between the two companies and the activists. The terms of these agreements will open the market to generic competition. The companies have agreed to license four additional companies to manufacture or import generic AZT and lamivudine products, with three companies being licensed to manufacture and/or import generic nevirapine products.

The agreements will have the effect of allowing government to procure antiretroviral drugs from a range of generic manufacturers without having to issue compulsory licences or negotiate voluntary licences first and will have a significant impact on prices.
OUTSTANDING CASES

\section{GAZI V. THE MINISTER OF PUBLIC SERVICE}

Dr Gazi, a medical practitioner in the Eastern Cape and the then spokesperson for health for the Pan African Congress (PAC), was found guilty of misconduct after he made various negative comments regarding the failure of the first Minister of Health to put an PMTCT programme in place. Dr Gazi appealled against the finding as well as the sentence, which amounted to a reprimand. The case has important implications for the rights of doctors who work in the public sector to speak out in the public interest and in the interests of their patients.

The case was argued in 2003 and a judgment is expected in 2004.

\section{A PREVIEW OF 2004}

A number of important cases will be heard in 2004 . These cases will, it is hoped, continue to develop the law relating to HIVIAIDS and also empower people with HIVIAIDS to use the law to redress unfair discrimination.

\section{NEGLIGENCE}

Three important cases dealing with medical negligence in the context of HIV are likely to be finalised in 2004. One case deals with the transplantation of a kidney from an infected person to a recipient without HIV. Despite requesting that HIV testing be conducted on both parties, medical practitioners preformed the transplant without confirming the HIV status of the donor. A claim for damages is pending against the hospital.

A second case concerns a newborn baby who was infected in hospital. A claim for damages, including access to antiretroviral therapy, is currently underway.

The third case concerns the failure of medical practitioners to ensure that HIV test results were communicated to a couple who were attempting to conceive a child. One partner was positive and subsequently inadvertently infected his partner, who was negative at the time of the test.

\section{SOUTH AFRICAN NATIONAL DEFENCE FORCE}

The SANDF continues to conduct pre-employment HIV testing and to exclude job applicants with HIV. The SANDF is excluded from the Employment Equity Act, which prohibits HIV testing in the workplace. It is our view that such testing is unlawful and unconstitutional, and a case challenging the requirement that new recruits are HIV negative will be argued in 2004. 